\title{
ENCUESTA SOBRE LA IDENTIDAD DE LOS MAPUCHES DE CHILE A LA LUZ DE LAS ETNIAS PERUANAS
}

\author{
Juan M. Ossio A.
}

En este ensayo se evalúa la encuesta CEP sobre identidad mapuche a la luz de los denominadores comunes con el panorama étnico del Perú. Para sacar a la luz esos denominadores, el autor se vale principalmente de los indígenas andinos que si bien a nivel consciente no reivindican una condición étnica diferente a la de otros peruanos, en la práctica mantienen creencias y comportamientos que sí muestran grandes contrastes socio-culturales. Para destacar su vigencia y arraigo en estos pueblos, se procura enlazar a estos denominadores en conjuntos significativos de modo que cada cual aparezca como complementario de los otros.

A partir de una revisión de la naturaleza de las relaciones sociales que domina en los ámbitos comunitarios donde transcurre la existen-

JuAn M. Ossio. Doctor en Antropología (Universidad de Oxford). Catedrático en la Pontificia Universidad Católica del Perú, Depto. de Ciencias Sociales. Miembro de Número de la Sociedad Peruana de Historia. Es especialista en religiones, estética y organización social de la sociedad andina, y ha escrito numerosos artículos sobre estos temas. Entre sus publicaciones más recientes destacan Los Indios del Perú (Madrid: MAPFRE, 1992) y Parentesco, Reciprocidad y Jerarquía en los Andes (Fondo Editorial de la Pontificia Universidad Católica del Perú, Lima, 1992). Su “The Idea of History in Felipe Guaman Poma de Ayala” será publicado próximamente.

N. del E.: Sobre los resultados de la encuesta mapuche realizada por el CEP (2006), véanse también en esta edición los trabajos de Fernando Zúñiga, Eduardo Valenzuela, Ignacio Irarrázaval y M. de los Ángeles Morandé, Aldo Mascareño, Rolf Foerster y Sonia Montecino, así como el comentario de Jorge Larraín al artículo de Aldo Mascareño y la presentación de Carolina Segovia y Lucas Sierra.

Estudios Públicos, 105 (verano 2007). 
cia de los pobladores más representativos de este segmento étnico, se destacan el rol de la reciprocidad y su relación con el sistema clasificatorio dualista de honda raigambre histórica. Asimismo, el autor se ocupa del mesianismo y la naturaleza de la religiosidad, el ciclo de desarrollo, las relaciones interétnicas, el poder político y aquel que se deriva de la esfera mágico-religiosa. Con este bagaje de información, se emprende la valoración de la encuesta CEP distinguiendo entre las preguntas de contenido descriptivo de las de opinión para destacar la viabilidad de cada cual. A renglón seguido, y con el propósito de comparar la tradicionalidad mapuche con la de los andinos, se analizan los contrastes que se dan entre los que viven en el medio rural y el urbano para pasar luego al conocimiento y práctica de cierta expresiones particulares de su cultura consignadas en la encuesta. Dado que en el caso andino el sistema de relaciones sociales ofrece importantes sugerencias para el conocimiento de la recreación de la identidad, se pone especial interés en las preguntas de la encuesta que tienen que ver con el matrimonio, la residencia, el parentesco y las migraciones. Finalmente se hace un intento por encontrar convergencias entre los artículos de Mascareño y aquel de Irarrázaval y Morandé, que ponen énfasis diferentes en el análisis de la encuesta.

\section{Globalización, homogenización y etnicidad}

$\mathrm{L}$

expansión de la globalización y la emergencia de conflictos entre grupos humanos que se identifican de étnicos han motivado que las ciencias sociales desarrollen un interés inusitado por las características de estos grupos particularmente en lo relativo a su cohesión y perdurabilidad en el tiempo. En América Latina, como en otras partes del mundo, además de atraer la atención ciertos grupos por su condición étnica lo hacen por ser descendientes de las poblaciones que existieron en sus territorios antes de la colonización europea.

El problema de fondo detrás del despertar de este interés está en la contraposición de tendencias homogeneizantes desatadas con una fuerza inusitada por la globalización, de un lado, y, por otro, la todavía masiva presencia de grupos humanos con sus propias particularidades culturales que se resisten a desaparecer. En otras palabras, lo que traduce esta contraposición es la posibilidad de mantener la diversidad cultural en un mundo competitivo que exige participar en la globalización para no quedar rezagado. 
En el caso de los herederos de las antiguas culturas pre-coloniales esta situación es más difícil pues a diferencia de otros grupos étnicos, como los europeos, que han podido marchar a un ritmo cercano a los de la globalización, su paso ha sido más lento, lo que explica que aparte de tener rasgos socio-culturales diferentes generalmente han devenido en los sectores más pobres dentro de los estados nacionales. Una razón importante para tener esta condición es sin duda el aislamiento, que puede tener su origen en razones engendradas por los mismos actores o en la presencia de tendencias excluyentes originadas en una tradición colonialista de la sociedad mayor de la cual son parte. Entre estas últimas las más comunes son privarlos de los servicios adecuados que benefician a otros integrantes de un estado-nación o dejarlos expuestos a los abusos de aquellos que tienen un mejor conocimiento de las reglas que permiten el funcionamiento de aquel organismo mayor.

En el periodo republicano peruano una expresión que adoptó la exclusión fue negarles su condición cultural diferente a los descendientes indígenas afincados en los valles interandinos y costeños. Es cierto que el lado oficial de esta exclusión no tuvo ninguna intención de dañarlos. Por el contrario, por un lado, trató de romper la discriminación de la que habían sido víctimas en el período colonial proclamando, de acuerdo a premisas liberales, que todos eran ciudadanos y por lo tanto iguales ante la ley y, por otro, buscar integrarlos vertical y nominalmente al nuevo estado independiente como parte de una nación unitaria. Desafortunadamente en la práctica al ignorarse las diferencias culturales, al no brindárseles los mismos servicios que recibían otros ciudadanos y mantenerse los prejuicios discriminatorios de antaño muchos indígenas terminaron en prisión por el simple delito de seguir practicando costumbres reñidas con la nueva legislación y, peor aún, avergonzándose de mostrar signos culturales que los podían diferenciar del resto de los peruanos.

Como consecuencia de estas circunstancias y otras que vienen de tiempos pretéritos, pocos son los indígenas andinos que reivindican una condición étnica diferente. Exceptuando los aimaras, son muy pocos los descendientes de las viejas etnias prehispánicas que poblaron los Andes que admiten una condición de indianidad y que se organicen en movimientos políticos que reivindiquen matices étnicos. De haber sido etnias y campesinos hoy prefieren la segunda de estas dos condiciones particularmente por la connotación clasista que encierra.

Por el contrario, los indígenas que habitan la Amazonía, dado que su participación en el sistema colonial español fue muy tenue y su grado de aislamiento ha sido mayor que los andinos, sí conservan sentimientos étnicos más acendrados y han aceptado con mayor facilidad aquellas organiza- 
ciones indianistas con que indígenas de distintas partes del mundo hacen prevalecer sus derechos ante los efectos de la globalización.

Pero que no reivindiquen los andinos una condición étnica no quiere decir que no ostenten diferencias culturales marcadas con respecto a los valores que comparten los pobladores que mantienen una participación más activa en la esfera nacional. Aunque el centralismo limeño haya empañado la visión de muchos políticos e intelectuales peruanos, en los valles interandinos todavía hay numerosos pobladores que pueden ser considerados como indígenas por conservar rasgos culturales y patrones de comportamiento no muy distantes de los que tuvieron sus antepasados prehispánicos. Es cierto que muchas veces se camuflan bajo modelos importados de Europa, pero basta una prolongada convivencia con estos habitantes para que un ojo aguzado descubra que por debajo asoman estructuras que mantienen una profunda continuidad en el tiempo y en el espacio.

Ante una circunstancia de esta naturaleza la indianidad de estos pobladores no es fácil descubrirse con un solo indicador. Por ejemplo, podríamos señalar que hablar una lengua vernácula originada en el pasado prehispánico puede ser un buen indicador. No dudo que es importante pero resulta que hay muchos sectores sociales, secularmente asociados con ámbitos urbanos, que la usan con gran maestría pero mantienen otros rasgos culturales que son más a tono con los que esgrimen capas sociales más cercanas a los valores nacionales como aquellos conocidos como "criollos”. Por otro lado, hay grupos que comparten una serie de rasgos comunes con pobladores vernáculo hablantes que viven en el medio rural pero que sin embargo no manejan ningún dialecto autóctono sino tan sólo el español.

Como hace algún tiempo lo destacó el antropólogo Fernando Fuenzalida, igual sucede con la ropa, los rasgos físicos, la música, etc. (Fuenzalida, 1970). En consecuencia para lograr acercarse a la condición indígena de los pobladores andinos la única alternativa es auscultarlos en sus contextos más íntimos como pueden ser las comunidades, que son fuente de recreación de sus tradiciones, y conjugar diversas variables bajo conjuntos significativos que permitan rastrear las continuidades en términos estructurales.

En el proceso de acopio de información por lo general lo primero que se busca es conocer la naturaleza de la organización social, política y económica para que a partir de detalles funcionales, quizá comunes a otros pueblos que encierran dinámicas sociales semejantes, se acceda a especificidades vinculadas más propiamente con la esfera cultural como pueden ser los ordenamientos clasificatorios expresados en las creencias, rituales, música, lenguaje y en general en lo que se considera cultura inmaterial así como también en los estilos de la cultura material. 
La encuesta a los mapuches y las etnias peruanas

Como se puede desprender de lo dicho anteriormente, si con alguna etnia peruana guardan semejanza los mapuches chilenos sería con aquellas que habitan la Amazonía peruana. Ambas tienen en común una cierta conciencia de ser diferentes a otros congéneres adyacentes a su territorio o del conjunto nacional cuando se llegan a considerar como parte de este último. Hago esta atingencia porque en el Perú hay muchos grupos no-contactados o con un contacto incipiente que no tienen ni idea de que son peruanos.

Pero hasta aquí las semejanzas pues difícilmente imagino que aquellas etnias amazónicas del Perú muestren un porcentaje tan alto de integración al conjunto nacional como se da entre los mapuches. Es cierto que nunca se les ha encuestado con un cuestionario tan elaborado como el que nos concierne en este artículo pero de lo que se conoce, salvo algunas excepciones como los Cocamas, no se han dado movilizaciones a las ciudades tan masivas como entre los mapuches y mucho menos a la ciudad de Lima. Pero, hablando de los contrastes entre ámbitos rurales y urbanos que son significativos para el grupo étnico chileno en el Perú, a éstos habría que agregarles uno adicional que es el del aislamiento ya que hay muchos pobladores indígenas que viviendo en un medio rural mantienen contactos muy diferenciados con el conjunto nacional. Adicionalmente, otra gran diferencia es que mientras los mapuches tienen el privilegio de ser prácticamente la etnia principal en la cual se contrasta el estado chileno, en el Perú no es sólo una sino cerca de 64 grupos dialectales repartidos en la selva en 1.354 comunidades y alrededor de 5 grupos dialectales distribuidos en los valles interandinos asentados en más de 5.000 comunidades.

Aunque las etnias del Perú presentan una problemática diferente a la de los mapuches creo que hay puntos comunes que pueden ayudar a concatenar desde nuevas ópticas la multiplicidad de preguntas que encierra la encuesta que se les ha dedicado. Con este propósito en lo que sigue analizaré el caso peruano poniendo énfasis en la etnicidad andina, pues aparte de que es la que mejor conozco encierra matices similares a la de los grupos amazónicos y marca grandes contrastes con la de los mapuches. Al terminar esta descripción acometeré la tarea de volver sobre la encuesta para precisar mejor los aportes que la realidad que me concierne ofrece a la lectura de muchas de las preguntas que contiene.

\section{Relaciones interpersonales y parentesco}

Siendo el modelo comunitario, heredado de las reducciones organizadas en el siglo XVI por el virrey Francisco de Toledo, el que tiende a 
concentrar a los herederos del periodo prehispánico que habitan los valles interandinos, las constricciones que ejerce en estos últimos son muy significativas. Dado que el número de pobladores que los habitan oscila entre las 100 y 500 (algunos mínimos casos hasta 5.000) familias y el territorio pocas veces llega a más de 10.000 hectáreas la naturaleza de la interacción social es lo que antropológicamente se conoce como interpersonal o "cara a cara". Esto significa que en el seno de estas unidades sociales todos se conocen y si a esto sumamos que propenden a la endogamia, todos están hasta emparentados entre sí.

En realidad el célebre sociólogo Ferdinand Tönnies podría haberse basado en estas últimas para desarrollar su modelo de Gemeinschaft pues efectivamente se trata de conjuntos sociales con una alta solidaridad entre sus miembros lo que lleva a que sólo entre ellos se tengan confianza y se recele de los extranjeros. Elocuente testimonio de esto último es un folklore que puebla los espacios allende estas comunidades con forasteros demoníacos que extraen la grasa de los comuneros para venderla a empresas industriales norteamericanas o europeas que manufacturan cosméticos, lubricantes o medicamentos que satisfacen los requerimientos del mundo exógeno en que se desarrollan. Los pobladores de habla quechua les dan el nombre de pishtacos o nacaq y los aimaras, qalasiri, y los atributos que les asignan alcanzan tal antigüedad que aparecen consignados en las antiguas crónicas del siglo XVI.

Indicadores de la importancia que alcanzan las relaciones de parentesco saltan a la vista a través del relieve que adquiere la herencia como medio de transmisión de los bienes, o por la presencia masiva de este tipo de allegados en la realización de actividades laborales como festivas, o en las difundidas creencias de índole mágico-religioso que sancionan los actos incestuosos, o en la multiplicidad de comportamientos prescritos que deben de desempeñar en ciertos contextos festivos algunos tipos de parientes entre los que destacan los yernos, los padrinos, ahijados y compadres, o en la permanencia de complejas terminologías de parentesco presentes en los dialectos vernáculos, en los elaborados ceremoniales que consolidan los compromisos matrimoniales, o en las estrictas pautas de guardar luto que obligan a las distintas categorías de familiares de un difunto.

Tal es la relevancia que estos vínculos alcanzan en estas unidades sociales que incluso la pobreza se vuelve sinónimo de ausencia de parientes como lo destaca el término quechua: huaccha, que designa tanto al menesteroso como al huérfano. $\mathrm{Y}$ es que efectivamente carecer de parientes es no contar con mano de obra disponible para desempeñar la multiplicidad de tareas que exigen sociedades como las que habitan los valles interandinos cuyas principales fuentes energéticas son la naturaleza y la fuerza de otros congéneres. 


\section{La reciprocidad}

a) Ayuda mutua y redistribución

Como suele ocurrir en sociedades donde predominan las relaciones sociales basadas en el trato interpersonal y el parentesco la reciprocidad se erige en un principio que invade los distintos dominios en que transcurre la vida de los pobladores. Es así que el conjunto de la vida social se puede ver como un proceso de prestaciones y contraprestaciones tal como el célebre sociólogo francés Marcel Mauss hacía referencia en su famoso ensayo sobre los dones. Como él decía, hablando de las sociedades que indebidamente se les llama primitivas,

Lo que intercambian no son exclusivamente bienes o riquezas, muebles e inmuebles, cosas útiles económicamente; son sobre todo gentilezas, festines, ritos, servicios militares, mujeres, niños, danzas, ferias en las que el mercado ocupa sólo uno de los momentos, y en los que la circulación de riquezas es sólo uno de los términos de un contrato mucho más general y permanente. Estas prestaciones y contraprestaciones nacen de forma más bien voluntaria por medio de presentes y regalos, aunque, en el fondo, sean rigurosamente obligatorias bajo pena de guerras privadas o públicas. (Mauss, 1971, p. 160.)

Para el caso andino podríamos añadir bajo pena de perder prestigio y verse, muchas veces, obligados a tener que salir de sus comunidades por convertirse en marginales de marginales. Éste es frecuentemente el caso de los huaccha que por carecer de parientes ni logran conseguir colaboradores para desarrollar sus actividades productivas y menos para asumir las responsabilidades festivas con que los individuos y sus familias afirman su prestigio en el seno de las comunidades. Los huaccha son como apestados. Unirse en matrimonio de acuerdo a las pautas endogámicas que rigen les resulta muy difícil porque nadie quiere desprestigiarse emparejándose con ellos y, por lo tanto, se ven privados del principal medio para acceder a la socialización plena.

Dada la importancia de las relaciones de reciprocidad los diferentes dialectos vernáculos han acuñado numerosos términos para dar cuenta de las distintas modalidades en que se presentan. En el quechua hablado en distintas partes de los Andes un término muy común es ayni. Igualmente es minca, que encierra algunos matices distintos al anterior. En el quechua de Cerro de Pasco y Huánuco, waje-waje está también ampliamente difundido. 
Unido a la "reciprocidad" también figura la "redistribución" que ha sido un término muy pertinente para caracterizar las obligaciones de estados prehispánicos, como el Inca, para con sus súbditos, o la lógica que está detrás de los modernos sistemas de cargos político-religiosos donde las nociones de prestigio y autoridad juegan roles importantes. Además este término también destaca el hecho que más importancia parece haber tenido el dar que recibir, lo que da pie para entender mejor las contraposiciones que se establecen entre estos sistemas y aquellos dominados por las tendencias del capitalismo y la economía competitiva del mercado donde la acumulación predomina frente a la generosidad.

Coincidiendo con las interpretaciones del antropólogo Lévi-Strauss sobre la importancia de la reciprocidad como factor explicativo del incesto, el mundo andino lo convalida proclamando que son susceptibles de condenarse, es decir de andar como almas errantes que devoran a seres vivientes, dos tipos de pecadores: los que cometen esta falta y los que son avaros. ¿Cuál es el común denominador de ambos? El poner freno a los intercambios recíprocos. Unos porque no permiten ampliar el círculo de las uniones matrimoniales y otros por interrumpir la circulación de los bienes.

\section{b) El dualismo}

Como ocurre en muchas sociedades donde la reciprocidad alcanza el rango de hecho social total su importancia es realzada adoptando un patrón organizativo donde todo cuerpo social destaca su condición unitaria presentándose como dividido en mitades institucionales cuya esencia es ser complementarias entre sí. Ya en el siglo XVII crónicas como "Los Comentarios Reales del Inca Garcilaso de la Vega, nos dicen:

...De esta manera se principió a poblar nuestra imperial ciudad, dividida en dos medios que llamaron Hanan Cozco, que, como sabes, quiere decir Cozco el alto, y Hurin Cozco, que es Cozco el bajo. Los que atrajo el rey quiso que poblasen a Hanan Cozco, y por esto le llamaron el alto; y los que convocó la reina, que poblasen a Hurin Cozco, y por eso le llamaron el bajo. Esta división de ciudad no fue para que los de la una mitad aventajasen a los de la otra mitad en exenciones y preeminencias, sino que todos fuesen iguales como hermanos, hijos de un padre y de una madre. Sólo quiso el Inca que hubiese esta división de pueblo y diferencia de nombres alto y bajo, para que quedase perpetua memoria de que a los unos había convocado el rey, y a los otros la reina; y mandó que entre ellos hubiese sola una diferencia y reconocimiento de 
superioridad: que los del Cozco alto fuesen respetados y tenidos como primogénitos hermanos mayores; y los del bajo fuesen como hijos segundos; y en suma, fuesen como el brazo derecho y el izquierdo en cualquiera preeminencia de lugar y oficio, por haber sido los del alto atraídos por el varón, y los del bajo por la hembra. A semejanza [...] hubo después esta misma división en todos los pueblos grandes o chicos de nuestro imperio, que los dividieron por barrios o por linajes, diciendo Hananayllu y Hurinayllu, que es el linaje alto y el bajo; Hanan suyo y Hurin suyo, que es el distrito alto y el bajo. (Garcilaso de la Vega, Inca, 1960, T. II, Libro 1, Cap. XV XVI, pp. 25-28.)

En el siglo XXI este patrón divisorio se mantiene por casi todas las comunidades andinas aunque no siempre las mitades en que se divide un territorio o un pueblo adopte los mismos términos que menciona el Inca. Unas veces pueden llamarse "allauca e ichoqa" (derecha e izquierda), otras “tuna y pata” (rincón y borde de un andén o terraza), “Huayla y Quechua”, “Checa y Concha”, “Qollana y Sawqa”, etc. Incluso hasta perduran mitos sobre el origen de estas divisiones que realzan su conexión con la reciprocidad como aquel recogido por el antropólogo Salvador Palomino que cuenta que en tiempos pasados

cuando no había Ayllus y todos eran iguales, las gentes han ido a Jajamarca para traer la campana María Angola y palos de níspero para la construcción de la iglesia, como todos eran iguales no había ánimo para trabajar y entonces pensaron — vamos a ponernos contra-contra, bueno tú vas a ser Qullana y nosotros Sawqa- y el Gobernador los repartió. Los Qullana trajeron la campana y es por eso que construyeron la torre a su lado (lado izquierdo de la iglesia)... (Palomino, 1984, p. 60.)

En otras palabras lo que el mito expresa es que la división fue un estímulo para el trabajo pues permitió la competencia, que unos rivalizaran con los otros y se acelerara el trabajo. Éste es el principio que impera en las faenas comunales y es principalmente en relación a estos contextos donde la división entre mitades, o múltiplos de ellas (como son las divisiones en 4, 6,8 y 10) se hace patente.

En la medida que la competencia es una expresión de la reciprocidad podríamos decir que es ella la que trae el dinamismo al mundo, el que a su vez asume la condición intrínseca del orden social. De aquí que todo cuerpo social se le represente como dicotómico y que las mitades sean el principal 
medio para expresar la recreación de la unidad de un cuerpo social como lo atestiguan estas competencias laborales u otras que asumen un carácter más beligerante como las batallas rituales. También es el caso de aquellos rituales como los que tienen que ver con la limpieza de los canales de riego cuyos pasos festivos se organizan en una secuencia que culmina en la contraposición de las dos mitades como para destacar la constitución paulatina de la unidad a partir de la diversidad de sus partes. De aquí también que el matrimonio sea considerado como un paso inevitable sin el cual la consecución de la plenitud de la socialización de los individuos es incompleta dada la rígida división del trabajo por género y su marcada complementariedad que los hace homologables a las mitades.

\section{c) Reciprocidad y economía de mercado}

Para la racionalidad forjada en las reglas del mercado y la economía capitalista muchas veces le resulta incomprensible comportamientos que bajo la lógica de la reciprocidad resultan explicables. No se comprende, por ejemplo, cómo un carnero que tiene una cotización en el mercado puede ser intercambiado por otro producto como una porción de papas que en este ámbito económico puede tener un precio menor. Menos se explica que existan comunidades que cultiven variedades de maíz que no tienen ninguna rentabilidad en el mercado y que para ello tengan que invertir miles de horas de esfuerzo para mantener la infraestructura que se le asocia.

¿Es que acaso están trastornados estos pobladores? Si se les juzga exclusivamente sobre la base de una perspectiva de la maximización de las ganancias, podría ser. Pero éste no es el caso. Los pobladores de la comunidad de Andamarca de la provincia de Lucanas del departamento de Ayacucho muestran con gran orgullo innumerables andenerías que demandan un titánico esfuerzo sólo para obtener magras cosechas de un maíz que por planta sólo produce una coronta. ¿Por qué desde casi tiempos prehispánicos siguen aferrados a las exigencias de este cultivo? Basta convivir un tiempo con ellos para darnos cuenta que el maíz es un instrumento vital para sostener las relaciones de reciprocidad. Con él se prepara la aqa o chicha que es una bebida que tiene la virtud de fortalecer los vínculos sociales. Ya Titu Cusi Yupanqui, en el siglo XVI, explicaba que si Atahuallpa había arrojado al suelo la Biblia que se le había alcanzado era porque previamente los españoles habían hecho lo mismo con la chicha que les ofreció en vasos de oro (Titu Cusi Yupanqui, 1973, pp. 15 y 16).

Pero el maíz no sólo se consume como chicha. Es también un ingrediente central en numerosos potajes u objetos con valor mágico-religioso 
que se preparan. Aparte de distraer al estómago como tostado (cancha) o mote es el ingrediente central del patachi, mondongo o sara pela que se sirve en ocasiones especiales e integra productos variados que se producen en las alturas como en las quebradas.

Además de haber dado lugar su cultivo a una tecnología especializada asociada con la conservación de la semilla y con las distintas etapas de su crecimiento, está rodeado de una cultura compleja que se proyecta al campo del arte textil, la cerámica, la madera y hasta la música.

En el mundo andino hay dos cultivos que por su importancia en distintos contextos, pero muy particularmente en aquellos en que se realza la reciprocidad, son considerados sagrados y por consiguiente dignos de asociarse con una multiplicidad de delicadas expresiones culturales. Estos cultivos son la coca y el maíz.

Ambos, por ejemplo, han dado lugar a mitos que hablan de sus orígenes o canciones donde se exaltan sus bondades. También a reglas de etiqueta que como en el caso de la coca pautan la forma que debe recibirse o, en el caso del maíz, la forma cómo debe desgranársele para lograr una buena cosecha. Asimismo alrededor de esta gramínea en muchas partes se desarrollan complejísimos rituales cuando se le siembra. La coca por su parte es almacenada en primorosas bolsas, llamadas chuspas o pijchas mientras que el maíz ha dado lugar a la confección de unas llamativas pecheras de color rojo con que arropan a la llama que lidera una tropa de sus congéneres cuando, con fines de intercambio, cargan sacos con este producto de un pueblo a otro.

Y así sucesivamente podríamos enumerar el vasto número de recipientes que se asocian con la elaboración de la chicha y con su consumo o con el almacenamiento de la cal que acompaña el chacchar o pijchar la hoja de coca. Pero si el maíz es tan realzado, otro producto agrícola como la papa, que también es de amplia difusión en los Andes, no tiene ni de lejos la compleja parafernalia que se le asocia al anterior. Ya desde antaño cronistas como Guaman Poma de Ayala la contraponían al homenajeado cereal destacando su falta de prestigio por su asociación con el Collasuyo, que frente al Chinchaysuyo era visto como más bajo. Asimismo existen numerosos mitos donde se le presenta como alimento de los pobres. Quizá la razón es que se trata de un tubérculo y como tal comparta la desventura de otras raíces que por pertenecer al subsuelo se les veía como alimentos de gente poco civilizada. Sin embargo hay que destacar que se trata de un cultivo ampliamente difundido y absolutamente vital para la dieta andina. Aunque las viandas a que ha dado lugar no gozan de tanto prestigio existen potajes que 
se preparan con determinadas variedades que hacen las delicias de los paladares más exigentes. Tanto es así que incluso motivan que se les dé un tratamiento especial y en el contexto de las relaciones recíprocas se las reserva para agasajar a personas con quienes se tiene un trato muy especial. Hasta se las singulariza calificándolas de "papa regalo".

Producir para fortalecer las relaciones de reciprocidad y poder acceder al mínimo indispensable para subsistir es algo que domina la vida de las poblaciones más aisladas. Ello sumado a las proclividades endogámicas es en gran medida fuente de los sentimientos autárquicos que pululan particularmente en departamentos como Ayacucho, Huancavelica, Apurímac, Cusco, Puno motivando que a toda esta área se la conozca como mancha india. La presión que ejerce la reciprocidad es tan fuerte que hasta los que tientan aventurarse por los caminos de la economía de mercado, como los propietarios de tiendas de abarrotes, no pueden dejar de lado estas consideraciones haciéndoseles muy difícil sus posibilidades de capitalizar cuando casi ningún cliente les paga de inmediato y a las deudas no se les añaden intereses. Hasta trasciende la esfera circunscrita de las comunidades y se expande a niveles nacionales con instituciones como la "yapa" que consiste en una pequeña adición que hace el vendedor al volumen de lo que se le compra como muestra de un trato interpersonal y amistoso.

Esto no quiere decir, sin embargo, que la reciprocidad cierre todas las posibilidades de participar en los mercados nacionales y extra-nacionales. Posiblemente si el aislamiento es dominante, su presencia es más intensa pero en los casos en que la apertura es mayor pareciera que el sistema social contase con resquicios flexibles que les permite un reacomodo a las exigencias del mundo extra-comunal. En Andamarca, por ejemplo, esto se ha logrado a través de la actividad ganadera que es la principal fuente para los ingresos monetarios. En otras partes puede ser a través del cultivo de papas, en otras por medio de los frutales y en unas más hasta por el turismo. Todo esto es indicativo que puede reconciliarse la tradición con la modernidad sin tener que producirse una disrupción de las unidades sociales, pero, eso sí, a costa de impedir el desarrollo de tendencias marcadamente individualistas y de un extremado ensanchamiento de los horizontes conceptuales.

Es muy posible que estas circunstancias expliquen las preferencias que muchos de los pobladores de estos ámbitos sienten hacia representantes de la política nacional que desarrollan discursos nacionalistas con inclinaciones autarquistas y colectivistas. Una muestra de ello lo hemos visto en las últimas elecciones presidenciales donde el candidato con discurso nacionalista Ollanta Humala casi ganó en primera vuelta, y casi obtiene el 
triunfo en la segunda, gracias al apoyo brindado por casi todas las provincias asociadas con los pueblos interandinos y muy particularmente con aquellas de la mencionada "mancha india".

\section{Mesianismo}

Estas elecciones, y otras anteriores, también han mostrado que los pobladores que venimos aludiendo tampoco dan señas de una mayor compenetración con los ideales de la democracia debido a ciertas inclinaciones por favorecer a candidatos que lucen un marcado autoritarismo. Es cierto que estas simpatías no las llevan a grandes extremos como se puede ver en el amplio rechazo que le dieron a la subversión desencadenada por Sendero Luminoso, pero si bien los fundamentalismos extremos, particularmente si son violentos, no les convence, existe cierta proclividad por ciertos líderes que se presentan con una aureola mesiánica.

La idea del restablecimiento del orden a través de un personaje que equilibra los opuestos complementarios y, por lo tanto, alcanza un rango casi divino ha sido muy recurrente en los Andes y calza estrechamente con la imagen que se tuvo del Inca, como Monarca Divino, en el pasado. Casi todas las rebeliones indígenas que se han sucedido en los Andes desde el siglo XVI han tenido como agentes del orden ya sea "huacas" o divinidades y al Inca. Hoy la muerte de este último, condensado en la figura de Atahuallpa, es representada en una diversidad de localidades y paralelamente existen infinidad de relatos orales, como el de Inkarrí, que sin especificar a un personaje histórico concreto dan cuenta de lo mismo pero haciendo hincapié en su resurrección y la restauración del orden. Todo ello sugiere que el recuerdo de este principio ordenador está bastante vivo y que puede reflotar en cualquier momento. Aunque rechazado por maniqueo, algo de ello exhibió Sendero Luminoso pero de manera más notoria, un movimiento religioso que he tenido la oportunidad de estudiar que se denomina la "Asociación Evangélica de la Misión Israelita del Nuevo Pacto Universal”.

La presencia de este principio ordenador está estrechamente ligada a una concepción que representa al tiempo como encapsulado en una sucesión de etapas inexorables por las cuales debe atravesar la humanidad. Esto explica que insistentemente se hable de retorno a los tiempos pasados o restauración del Imperio Incaico. En realidad no se trata de un retorno a un tiempo histórico propiamente dicho sino a una condición utópica caracterizada por la imagen de orden. 
Ya desde la época prehispánica las crónicas nos hablan que se creía que el presente se ubicaba en una quinta edad que, como las que la habían precedido, culminaría en un cataclismo conocido como "Pachacuti". Producida la conquista tal fue la disrupción que causó que se pensó que se había cumplido esta catástrofe cósmica que todos esperaban. Unida a esta creencia se reforzó la expectativa que sólo un principio ordenador proporcional a la magnitud del fenómeno que había engendrado el desorden podría restablecer el equilibrio perdido. Como por sus atributos lo más cercano era el Inca, pronto la esperanza se centró en su retorno constituyéndose en el principal ingrediente de los movimientos mesiánicos que se sucedieron a lo largo del tiempo.

Hoy la idea que el tiempo está dividido en un número de edades fijas se mantiene aunque camuflada bajo tradiciones venidas de Europa como aquella expuesta por Joaquín de Fiore y difundida por los franciscanos que habla de una era del Padre, otra del Hijo y que vendrá una tercera que es la del Espíritu Santo. Una primera muestra de cómo esta tradición se aunó a la del mesianismo andino se ve en los símbolos que adoptó Juan Santos Atahuallpa en el levantamiento que originó en la primera mitad del siglo XVIII. A través de ellos vemos que aparte de autodenominarse Atahuallpa por el último Inca incorpora el de Santos en alusión a la tercera Persona de la Trinidad que en el esquema Andino alude a una edad casi celestial que vendrá después de la presente que es la del Hijo o, en su caso, después de su rebelión.

Habiéndose producido esta transición nuevas variantes pudieron desarrollarse tanto que a mediados del siglo XX vemos aparecer un movimiento, el ya mencionado de los israelitas del Nuevo Pacto Universal, donde el líder se proclama como la encarnación del Espíritu Santo y ofrece salvar a la humanidad de un eminente cataclismo, modelado en las enseñanzas del adventismo, que debía ocurrir en el año 2000 o cuando Dios se lo comunicara. Aunque nunca declaró que era un Inca, pero muchos detalles lo sugirieron, cuando incursionó en la política para alcanzar la Presidencia de la República el modelo de sociedad que propuso era uno consonante al viejo Tahuantinsuyo donde imperara el colectivismo y la principal fuente de ingreso fuese la agricultura.

El nombre de este personaje fue Ezequiel Ataucusi Gamonal, una persona muy carismática de condición indígena quechua-hablante, nacido en una comunidad de las alturas del Departamento de Arequipa. Su prédica la inició en la ceja de la montaña a mediados de la década de los 50 pero al final del siglo XX se calcula que reclutó más seguidores que cualquiera de las agrupaciones no-católicas que existen en el Perú. Siendo la mayor parte 
de ellos de su misma condición socio-cultural pronto arraigó en su imaginario que él era no solamente un nuevo Cristo sino el Inkarrí del mito ya mencionado.

Por otro lado, tengo la impresión de que si Cristo fue aceptado en los Andes no fue tanto como redentor que con su muerte liberó a la humanidad del pecado original abriendo las puertas del Cielo sino sobre todo por su vertiente como Monarca Divino y como tal con la potestad de salvar a la humanidad frente a cataclismos. Una muestra de ello es la asociación que se hace tanto en Lima como en el Cusco de la imagen del Señor de los Milagros con terremotos, la cual alcanza un relieve que está a la altura de aquella que alcanza la Virgen de Guadalupe en Méjico.

\section{Religiosidad}

Si en algo tuvo éxito la intensa prédica católica en los Andes fue en lograr sustituir las antiguas huacas o divinidades que se veneraban en el período prehispánico por los santos. Una razón para ello es que supieron mantener el viejo rol de clasificadores totémicos que habían tenido aquellas antiguas expresiones de su religiosidad. A partir de la dominación europea los santos se convirtieron en los nuevos demarcadores del espacio, del tiempo y de las relaciones sociales. Al igual que las antiguas huacas, o como sigue siendo el caso con las montañas, ellos también se jerarquizaron de acuerdo a la extensión de su ámbito de influencia, pautaron las actividades que se debían de realizar durante el año y ordenaron el espacio, y hasta los mismos individuos, socializándolos bajo su patronazgo. Así como los seres humanos se comenzaron a llamar Pedro, Juan, María, Carmen, etc., también las distintas unidades sociales se identificaron como San Cristóbal, Espíritu Santo, la Veracruz, San Andrés, etc. y las festividades conmemorándolas se convirtieron en las fiestas patronales y sus auspiciadores en los mayordomos, alféreces o priostes.

En lo que sí no alcanzó mayor aceptación fue en la noción de pecado y su correlato de castigo y recompensa en el más allá. Menos aún en lo concerniente a la doctrina subyacente a los sacramentos empezando por el bautismo. Tan difícil fue este adoctrinamiento que los pocos equivalentes quechuas que encontraron en un principio para transmitir estas ideas tuvieron que castellanizarlas muy rápido. Es así que pronto la vieja noción de camaquen para alma fue sustituida por ánima. En otros casos encontraron equivalentes pero cuyas acepciones eran bastante diferentes al sentido otorgado en el cristianismo. Por ejemplo para pecado acuñaron huchay, que efectivamente tenía la connotación de falta pero que de ninguna manera 
implicaba que se le aparejase un lugar de castigo en el más allá. Para los andinos, como para muchos pueblos, las transgresiones se pagaban en esta vida. Enfermedades, muerte de seres queridos y otras desventuras eran el precio por quebrantar normas morales. De ninguna manera el ir a un infierno o un purgatorio. Hasta el presente "condenarse" no quiere decir que el alma se vaya al infierno sino que ande errante poniendo en peligro el orden de los seres vivientes. Además no cualquiera se condena. Son principalmente los incestuosos o amarretes los más susceptibles de sufrir este castigo que tampoco es concebido como eterno. Un "condenado" siempre cuenta con alternativas para dejar este estado. Unas veces puede ser porque se devora a tres seres humanos, otras porque lucha con un personaje que lo supera en sus fuerzas.

Después de muerto el destino de toda alma de un adulto, sea de buenos o malos, es irse a una montaña que se llama Coropuna. Allí construyen una torre que cuando está por terminarse se viene abajo. Para ayudarla en esta travesía se organizan rituales complejos en que se le hace un muñeco en forma de llama que se le carga con comida para que no pase hambre. Todos los pasos que se dan es para que el alma no retorne al mundo de los vivos pues si lo hace es porque cometió algún pecado que lo transformó en condenado. Un punto culminante que no dejan de hacer sea que se hayan convertido a otra religión es lavar la ropa del muerto. Se trata de un acto imprescindible para lograr la separación total y evitar el tan temido retorno.

En relación a los adultos éste es el sentido que tienen los ritos funerarios. El difunto o difunta debe ser alejado de los vivos y los parientes cercanos cumplir con las exigencias de guardar luto. Pasado cierto tiempo ya no sólo es temor lo que lleva a recordar a los muertos y celebrarlos el 1 de noviembre sino contar con protectores que les deparen fortuna en sus diferentes quehaceres.

Los niños bautizados, por su parte, si mueren sin desarrollar sus potencialidades sexuales y, por lo tanto, de incurrir en incesto son enterrados como "angelitos". Es sólo en relación a ellos que la "Gloria" o el "Cielo" se presenta como morada post-mortem. Sin embargo pueden acceder a este destino no porque con el Bautismo hayan sido liberados del "pecado original" sino porque a través de este ritual han accedido a la etapa inicial del proceso de socialización. Es decir, a una etapa donde se les singulariza con un nombre, para la cual han necesitado de padrinos, y que les permite ingresar a una posición en el conjunto social.

Los niños que mueren sin estar bautizados, por el contrario son seres no sociales que no pueden ser enterrados en espacios socializados como los cementerios y sus almas tienen como destino un sitio oscuro cuyas piedras maman por la eternidad. 


\section{El matrimonio y la socialización plena}

El tratamiento y creencias alrededor de la muerte según las distintas etapas del ciclo de desarrollo de los individuos ponen de manifiesto que estas últimas son concebidas como un paulatino proceso de socialización donde la plenitud se alcanza con el emparejamiento institucionalizado. Un primer indicador del acceso a la condición adulta es el desarrollo del potencial sexual que puede traer aparejado el incesto y, por lo tanto, el peligro de la condenación. Es por esta razón que los que mueren habiendo llegado a esta etapa son enterrados como adulto. No lo son, sin embargo, porque se considera que las relaciones sexuales sean pecaminosas sino porque los que se involucran puedan estar emparentados entre sí.

Ya desde el siglo XVI los españoles se quedaban impresionados de la liberalidad sexual que se daba entre los andinos al punto que la virginidad de las mujeres era desdeñada por los varones por sugerir la existencia de anomalías que las hacían poco apetecibles. Hoy entre los adolescentes de las comunidades andinas se mantiene la misma liberalidad de antaño siendo el temor al incesto la única restricción que los inhibe. A lo largo del año existen numerosos contextos festivos que propician estos amoríos y las estadísticas señalan que nueve meses después de tales eventos se incrementan los nacimientos de niños. Esto no quiere decir, sin embargo, que los involucrados en estos romances a la larga terminen contrayendo matrimonio. La razón es que no siempre la decisión reposa en los contrayentes. La mayor parte de las veces depende de los padres llegando en algunas partes a reconocerse prácticas donde los últimos en enterarse que se desposarán son los mismos contrayentes. La razón es que el matrimonio en los Andes no sólo une a individuos sino a grupos.

Dada la rígida división del trabajo, con el matrimonio los contrayentes acceden a la plenitud del orden social y sus respectivas familias robustecen sus vínculos. Se trata de un momento muy importante para todo individuo, razón por la cual su consolidación está rodeada de complejas ceremonias que se hacen en sucesivas ocasiones. Una primera es el acuerdo que se sella entre las familias de los novios. A partir de esta primera instancia de legitimización la pareja puede iniciar una convivencia que por lo general se hace en la casa de los padres de la novia. A esta etapa se le denomina en algunas partes servinakuy porque el yerno está obligado a servir a su suegro en lo que este último requiera. Su duración es variable dependiendo de la capacidad de acumular el dinero suficiente para celebrar la bendición por la iglesia que es la que conlleva los mayores gastos. 
El matrimonio religioso supone el reconocimiento del conjunto de la colectividad comunal. Exige, por lo tanto, de una gran concurrencia que deba ser agasajada y que participe en los múltiples festejos que se organizan entre los cuales adquieren una gran relevancia la entrega de obsequios consistentes en dinero. Luego de los múltiples días que duran estas celebraciones el rango de adultos es adjudicado a la pareja lo que significa que a partir de este momento sus obligaciones no son sólo para el seno familiar sino para el conjunto de la sociedad. Ello explica que sean destinados a pasar ciertos cargos comunales iniciales que sólo están reservados para los recién casados.

A medida que su vida conyugal se inicia poco a poco hacen abandono de la casa de los padres de la novia para forjar una residencia independiente. Seguir mostrando esta dependencia puede acarrearle molestos comentarios al varón y hasta los temidos insultos de "saco largo" o raka qati (seguidor de la vagina) que afrentan el rol dominante que debe tener el varón frente a la mujer.

Poco a poco comienzan a llegar los hijos y es muy común desear que el primero que nazca sea mujer. La explicación que dan es que la mujer es taje o depósito de alimentos y si se materializa este deseo la recién nacida traerá abundancia al hogar.

Con el nacimiento de los hijos no solamente se incrementa la familia sino los vínculos sociales pues cada vástago debe pasar por distintos ritos de pasaje que suponen la presencia de auspiciadores o padrinos con los cuales se cimientan relaciones de compadrazgo. Primero es el ya mencionado Bautismo, luego el corte de pelo, y dependiendo de cada localidad, otros más que van incrementando la red. Es así que una pareja se va haciendo de una amplia red de personas que han auspiciado rituales para sus hijos pero también de otros a quienes ella ha servido en esta condición. Si su fama como pareja responsable y juiciosa se expande, es solicitada por cantidades de nuevos cónyuges para que apadrinen su matrimonio pues saben que en ellos encontrarán el consejo adecuado para superar las posibles desavenencias que suelen ocurrir.

Cuando los hijos comienzan a casarse una pareja matrimonial por lo general ha llegado al ápice de la expansión de sus redes sociales y también de acumulación de bienes. Luego estos últimos comenzarán a desmembrarse para pasar a manos de los hijos. Esta etapa cumbre de la acumulación de vínculos y bienes es el momento más adecuado para pasar los cargos festivos más onerosos. Se trata de un momento en que sus éxitos se tienen que hacer patentes y al asumir los retos de una obligación pública que recrea la solidaridad de todo el conjunto comunal del que es parte no sólo realza su 
prestigio sino que puede mostrar que sus redes sociales son casi co-extensivas con las del conjunto de la comunidad. Pasado cierto tiempo se convertirá en un "cargo pasado” y como tal en un custodio del orden moral de su sociedad.

\section{El poder político}

Tener una amplia red de relaciones sociales y saberla convocar para determinadas situaciones es un signo de poder y explica por qué el sistema de autoridades tradicionales, conocidos como varayoqs o "envarados" o “alcaldes pedáneos”, asume una naturaleza escalonada que progresa con las edades de las personas de peldaños con proyecciones circunscritas a otros más amplios y de mayor jerarquía. En la comunidad de Q’eros, por ejemplo, la jerarquía de posiciones se inicia con los Collana que deben dar el ejemplo en toda obra comunal y es ocupada por los recién casados. Luego siguen los alguaciles que son los ayudantes de los regidores y el alcalde, y culmina con el alcalde cuya esfera de responsabilidad es el conjunto de la comunidad. Esta posición es ocupada por personas mayores que como en el caso ya visto de los mayordomos para ocasiones festivas han llegado a la cúspide de la acumulación de vínculos sociales.

En comunidades aisladas como la de Q'eros donde predominan las relaciones de reciprocidad el poder casi unívocamente se deriva de este ensanchamiento de los vínculos sociales lo cual impide la concentración del poder en determinadas familias. Esto último ocurre cuando se entrometen factores exógenos. Las encomiendas, las haciendas, fueron antes algunos de estos factores pero aparte de éstos, que tuvieron un origen en la esfera privada, existen otros provenientes del Estado.

La principal intromisión del lado público en el período republicano viene del hecho que las comunidades son también parte de las demarcaciones políticas que éste ha creado. En consecuencia, como por lo general la circunscripción que se les superpone es el distrito o los anexos de distrito aparte de las autoridades tradicionales, se les agregan los gobernadores o tenientes gobernadores, los alcaldes o tenientes alcaldes, los jueces de paz y algunos más. Adicionalmente, como paulatinamente se les va adjudicando una personería jurídica, siempre y cuando cumplan con ciertos requisitos, que les permite buscar el amparo del Estado, existe otra tanda de funcionarios asociados a esta condición que se les agregan. Es el caso de la Junta de Administración y la Junta de Vigilancia que cuentan con sus respectivos presidentes y varios otros funcionarios. 
¿Quiénes devienen en las autoridades de estos marcos institucionales que se originan en el Estado nacional? La respuesta es muy simple, en primer lugar aquellos que califican con los requerimientos que acompañan a las posiciones públicas. Uno muy importante es saber leer y escribir lo que significa que aquellos que puedan aspirar a desempeñar las funciones exigidas tienen que haber pasado por el sistema formal de enseñanza impartido según los cánones del Estado.

A los viejos mecanismos para acceder al poder ahora vemos que se le agrega una nueva variable. Ésta es la educación y en general el conocimientos de las reglas de juego allende el ámbito comunal. Si a estos factores culturales se les añade la capacidad de expandir las redes sociales más allá del ámbito comunal hasta el provincial e, incluso, el departamental o nacional, el poder llega a ser omnímodo. En la práctica han sido circunstancias de esta naturaleza las que están detrás de aquellas relaciones interétnicas, muchas veces conflictivas, que aparecen tan recurrentemente en las novelas de José María Arguedas.

\section{Relaciones interétnicas}

Las relaciones entre pobladores oriundos a las comunidades y otros venidos de afuera no son nuevas. Existen desde la aparición de los estados prehispánicos y la emergencia de aquellos colonos que recibieron el nombre de mitmac. Ya en los documentos antiguos vemos que a los primeros se les denominaba Huaris y a los otros Llacuaces. De los autóctonos se decía que habían emergido de cavidades o Pacarinas, ubicadas en el territorio que poseían, que eran agricultores y veneraban a un dios llamado como ellos. Los forasteros, por el contrario, derivaban sus orígenes del lago Titicaca, se les asociaba con la actividad ganadera y con el culto al rayo. Ambos grupos convivían en los pueblos y por tener algunas prácticas un tanto diferentes los extirpadores de idolatrías aconsejaban que se los distinguiera.

Hoy los venidos de afuera son llamados qala, lanchi pero más comúnmente misti. El primero de estos términos alude a desnudo, despojado de ropa, lo cual, dada la importancia social del vestido en los Andes, sugeriría que se les percibiría como no sociales. Correspondientemente la valoración que se les da no es nada positiva. De ellos se dice que llegaron huyendo de la justicia y que aprovechándose de la ignorancia de los comuneros los despojaron de sus propiedades. Unos llegaron al extremo de decirme que no había mistis buenos, lo que coincide con la imagen que José 
María Arguedas transmite en sus novelas y cuentos sobre estos personajes.

Que valiéndose de un mejor conocimiento de las reglas del juego legal a nivel nacional les haya permitido hacerse de las propiedades de los indígenas es muy plausible. Teniendo mayor poder adquisitivo por participar más intensamente en los mercados extra-locales les daba la capacidad de actuar de prestamistas, particularmente cuando los campesinos pasaban cargos. Al no poder cumplir sus obligaciones a tiempo y haber dado sus propiedades como garantía estas últimas terminaban perdiéndose.

Es que los mistis en realidad era un sector social más cercano a los patrones culturales del sistema nacional. No sólo ostentaban apellidos de origen hispánico sino que hablaban el español y el quechua con fluidez aunque este último manejaba un corpus terminológico y una entonación muy distintos al de los autóctonos. Igual sucedía con la música vernácula que entonaban y sumado a todo esto sus redes sociales no se circunscribían a la localidad donde estaban asentados sino que se expandían a nivel de la provincia y hasta del departamento.

Dadas estas características este sector socio-cultural era el más adecuado para ocupar las posiciones políticas asociadas con la demarcación política del Estado. Hasta el gobierno de Juan Velasco Alvarado ellos eran los que casi monopolizaban cargos tales como gobernador, alcalde, juez de paz. Dependiendo su nombramiento de ternas enviadas a las autoridades departamentales, tenían grandes oportunidades de obtener lo que aspiraban por ser estas instancias decisorias eslabones de sus redes sociales.

En buena parte de los departamentos de Ayacucho, Huancavelica y Apurímac, coincidiendo con las características de los antiguos llacuaces los mistis obtenían sus ingresos económicos principalmente de la actividad ganadera. Particularmente de la crianza de vacunos. No era que tuviesen el deseo consciente de imitar a sus homólogos del pasado sino que dada la orientación tradicional de la agricultura la actividad ganadera era la que con más fuerza había ingresado a los circuitos económicos del mercado por la demanda de carnes rojas y algunos productos lácteos como quesos.

Compartiendo con los indígenas la tendencia hacia la endogamia, ambos grupos terminaron estratificándose en capas sociales que, por semejanza a las existentes en la India, recibieron la denominación de "casta”. No obstante debe precisarse que en el seno de las comunidades los mistis constituían una minoría. En Andamarca ellos representaban el 3 o 4\% del total de familias, pero se les identificaba fácilmente porque sus residencias tendían a concentrarse en la plaza o en una calle central donde pululaban los establecimientos comerciales. Por todas estas consideraciones a pesar 
de que su establecimiento en la zona venía de tiempos inmemoriales, nunca perdían su identificación como foráneos y, como tales, la conservación de un cierto barniz de ilegitimidad.

Tan acendrada es esta oposición entre lo local y lo foráneo que por lo general peruanos provenientes de la costa, particularmente de los barrios residenciales de Lima, no son reconocidos como compatriotas por los pobladores andinos aun presentando sus documentos de identificación. Para estos pobladores estos peruanos al igual que un norteamericano o europeo son "gringos". La peruanidad deviene, por lo tanto, en un patrimonio de ellos no de los que se asocian con los valores de los segmentos más altos que son vistos como "blancos" y ricos y provenientes de los barrios residenciales de la capital.

Con la pérdida de popularidad de los viejos partidos políticos y el advenimiento de independientes, a partir de 1990 se ha visto cómo estas consideraciones de corte étnico han estado cada vez más presentes en las elecciones presidenciales del Perú. Por ejemplo es notorio que en la confrontación entre Mario Vargas Llosa y un desconocido rector de la Universidad Agraria la Molina, de origen japonés este último recibió un masivo apoyo de los departamentos y provincias más andinos del país. Parecía como si se hubiera querido castigar el cosmopolitanismo del escritor convalidando la prédica de los adversarios que era el candidato de los ricos y blancos mientras que su rival era el "chinito que iba acompañado de cholitos”. Últimamente también se ha visto algo semejante, pues mientras Humala recibió una mayoritaria adhesión de departamentos y provincias andinas, Alan García apenas si lo pudo ganar con el apoyo del Departamento de Lima, otros departamentos costeños del norte y los peruanos afincados en el extranjero. Cinco años atrás, en cambio, Toledo manipulando conscientemente su origen indígena, logró triunfar atrayendo a los mismos contingentes que votaron por Humala, pero además a los que reconocían su valor como demócrata por su denodada lucha contra el fujimorismo.

Esta tendencia mesiánica a votar más por personas que por partidos políticos sólidamente constituidos traduce una falta de participación en cauces extra-locales de la vida política nacional. Incluso los sindicatos que antes pudieron cobijar a pobladores de las comunidades campesinas han perdido prestigio. En su lugar algunas organizaciones de corte indianista, como las que existen para los grupos amazónicos y para los indígenas de otras partes del mundo, tratan de abrirse paso pero sólo han alcanzado cierto éxito entre los aimaras del sur del Perú y muy tibiamente entre los Ancaras de Huancavelica. La verdad que para la mayor parte de indígenas andinos no existen organizaciones extra-comunales sólidas sean políticas o 
de otro índole que los aglutinen. Como correlato su participación en la política nacional es muy precaria y en todo el período republicano sólo una persona, concretamente una aimara, ha podido llegar al Congreso de la República.

\section{La esfera mágico-religiosa}

A la par del poder que otorga la amplitud de las relaciones sociales o el conocimiento de las reglas de juego de la sociedad más global, una fuente adicional son las creencias mágico-religiosas que han permitido la continuidad de ciertos especialistas que pueden curar enfermedades así como también ocasionarlas, predecir el futuro, descubrir los robos y muchas otras cosas más. En el Cusco reciben nombres como Alto Misayoq, Kuraq Aculli y unos más. En Ayacucho se les conoce como Pongo, Auqui. Entre los aimaras el más común es yatiri. Aparte se les adjudica términos derivados del español como “curanderos”, “curiosos”, "hueseros”, “comadronas”, etc.

Aunque es frecuente la presencia de factores hereditarios, en lo que verdaderamente se hace hincapié es en que las habilidades son innatas y se descubren de acuerdo a situaciones fortuitas como sobrevivir a la caída de un rayo, o de una enfermedad o accidente mortal, o recibir revelaciones en los sueños. Por lo general, estas circunstancias ocurren cuando se es muy joven por lo que una vez consciente de sus potencialidades se busca a un maestro para que lo entrene. El período de aprendizaje es variable pero por lo general se accede a una gran reputación cuando se llega a la madurez.

En el mundo andino los especialistas en estos menesteres son muy numerosos y variados. Obviamente si son populares es porque mucha gente cree en ellos y participa de un sistema de creencias mágico-religiosas vinculadas al bienestar de las personas que no son parte del aparato conceptual que maneja la medicina académica. Enfermarse por pensar que los ha atrapado la tierra, o les han robado el alma, o han sufrido un gran susto o una gran vergüenza, no son causas para las cuales los médicos del sistema formal estén preparados a tratar. Menos son terapias como frotar un cuy, o un huevo, hacer ofrendas a la tierra u otras divinidades, o jalarle los pelos a un paciente o beber pócimas donde hay culebras, y otros ingredientes de naturaleza semejante o plantas medicinales. Sin embargo, si las personas se enferman bajo las causales señaladas y no las tratan con los procedimientos correspondientes, se llegan a morir.

Pero acudir a curanderos, que en el Perú lo hace un altísimo porcentaje de la población, no quiere decir desconocer las bondades de la medici- 
na académica. Los médicos, cuando los hay, son siempre bienvenidos en las comunidades campesinas, sin embargo como no siempre están a mano y muchos no comprenden la naturaleza de sus enfermedades vernáculas optan por ir a los curanderos.

\section{La encuesta y el orden de presentación de los datos}

A estas características de los indígenas andinos podríamos sumarles varias otras derivadas de sus tradiciones orales, canciones, bailes, hábitos culinarios, juegos, ritos públicos y privados que, como en el caso de la encuesta para los mapuches, serían muy útiles para ayudar a esclarecer la identidad de los pueblos andinos pero por el momento he preferido caracterizar a los indígenas andinos del Perú valiéndome de ciertos rasgos estructurales que ayudan a explicar la permanencia de valores étnicos heredados del pasado. Entre éstos he destacado la presencia de ciertos indicadores que dan cuenta de la importancia de las relaciones de parentesco, de las relaciones de reciprocidad y de la vigencia de aparatos conceptuales sustentados en premisas mágico-religiosas sobre los que se montan y adquieren más sentido otros, estudiados por el folklore, que han sido vistos como reliquias deshilvanadas del pasado.

No obstante, si a estos herederos andinos del pasado prehispánico, excluyendo a los aimaras, se les pregunta por su afiliación étnica, no saben qué responder. Dependiendo de distintos contextos, ellos podrán reivindicar que son runas, que es un término quechua equivalente a ser "humano". Más inclusivamente destacarán su afiliación a la comunidad donde pertenecen, o al distrito, la provincia, el departamento y finalmente se reconocerán como peruanos. En este sentido están muy lejos de los mapuches, de las etnias amazónicas y también de algunas etnias andinas del Ecuador. Sea porque la historia de este último estuvo menos expuesta a los procesos homogeneizadores que impactaron en el Perú, lo cierto es que grupos como los otavalos y cañaris todavía son visibles y reivindican su condición de etnias.

Pero si bien los andinos del Perú presentan una problemática diferente a los grupos del párrafo anterior, una aproximación como la que he intentado me parece que puede ayudar a entender más claramente los datos de encuestas como la de los mapuches. Correspondientemente me he permitido reordenar la multiplicidad de preguntas distinguiendo en primer lugar aquellas de naturaleza descriptiva, como pueden ser la edad, los estudios, 
etc., de aquellas que implican dar una opinión; y, en segundo lugar, tratar de verlas bajo una secuencia donde se empieza por aquellas que aluden al manejo de expresiones culturales muy íntimamente vinculadas con la condición de mapuche como el idioma y ciertos rituales y prosiguiendo con otras que traducen algunos aspectos de sus sistemas sociales como los apellidos, las prácticas matrimoniales, la transmisión de bienes y la cooperación recíproca.

El haber seleccionado a 1.487 mapuches y haberlos cotejado con otros 1.487 no-mapuches que viven en áreas aledañas me ha parecido una magnífica idea para poder controlar mejor las peculiaridades propias de los mapuches. Sin embargo, siendo estas poblaciones muy cercanas entre sí, y por lo tanto con grandes posibilidades de influirse mutuamente, quizá un mejor control de la información se hubiese conseguido comparando los resultados con otros 1.487 no-mapuches seleccionados de áreas más distantes.

Comprendo que esto último quizá hubiese significado complicar esta encuesta que, como se puede apreciar, ya es bastante abultada sino también los múltiples cruces que pueden realizarse. Al respecto hay que destacar que no sólo se ha trabajado una muestra bastante representativa del conjunto poblacional mapuche (que al parecer está cerca de los 600.000 o cerca de un 5\% del total de la población de Chile) sino también de aquellos que están repartidos entre ámbitos urbanos y rurales y entre las regiones donde alcanzan un mayor predominio. Además se han añadido variables como género, edades y años de escolaridad.

Un indicador significativo de los cambios que se ha operado en el pueblo mapuche es que según el censo del 2002 un 61\% de esta etnia vive en medios urbanos y sólo el 30\% en los rurales. No obstante, en la Araucanía que es la región donde están más concentrados el 25,6\% vive en el campo mientras que el 9,3\% en la ciudad. En la X Región también los que viven en el medio rural ganan ligeramente a los que habitan ámbitos urbanos (10,3\% a 8,3\%). Sólo en la VIII Región los que residen en localidades urbanas tienen un mayor porcentaje en relación a los que radican en el campo. Los primeros representan un 6,3\% y los segundos un 2,8\%.

Pero lo más asombroso es el altísimo porcentaje de mapuches que han migrado a la capital. El que sean un 37\% los hace incluso un poco más mayoritarios de los que decidieron permanecer en la región de origen más importante donde son el 34,9\%. Como ocurre frecuentemente con este tipo de migraciones una vez en la ciudad los hombres se dedican al comercio y las mujeres a los servicios como se puede ver en el censo del 2002. 
CUADRO N ${ }^{\circ}$ 1: $\quad$ PROPORCIÓN REGIONAL DE LA POBLACIÓN MAPUCHE

\begin{tabular}{|c|c|c|c|}
\hline Región & $\begin{array}{c}\text { Población mapuche } \\
\text { Total }\end{array}$ & $\begin{array}{c}\text { Población mapuche } \\
\text { Urbana }\end{array}$ & $\begin{array}{c}\text { Población mapuche } \\
\text { Rural }\end{array}$ \\
\hline
\end{tabular}

$\begin{array}{lrrr}\text { Del Bío-Bío } & 9,1 \% & 6,3 \% & 2,8 \% \\ \text { De la Araucanía } & 34,9 \% & 9,3 \% & 25,6 \% \\ \text { De Los Lagos } & 19,0 \% & 8,7 \% & 10,3 \% \\ \text { Metropolitana de Santiago } & 37,0 \% & 36,4 \% & 0,5 \% \\ \text { Total } & 100 \% & 60,7 \% & 39,3 \%\end{array}$

* Población de 18 años y más Censo 2002, Instituto Nacional de Estadísticas.

No obstante, el que todavía permanezcan en el campo en la IX Región en un gran porcentaje podría tener como consecuencia que la Araucanía esté deviniendo en la principal fuente de recreación de su cultura como veremos a continuación.

Un primer efecto que parecen haber tenido los grandes cambios a los cuales ha estado expuesta la sociedad mapuche es que muchos de sus miembros han perdido el conocimiento de su idioma. Según la encuesta, un $56 \%$ de la muestra ni la habla ni la entiende y para que se vea el efecto de la migración a las ciudades el 64\% de éstos radica en medios urbanos. Es sólo en la IX Región donde se concentra la mayor parte de la población que lo habla la que, como hemos visto, es la de mayor número de mapuches en el campo. Sin embargo un indicador de su proceso de debilitamiento es que sólo un $18 \%$ lo hable todos los días y que principalmente lo hagan los que tienen baja escolaridad. Además es interesante observar que el principal estímulo para practicarlo sean los abuelos y que la diferencia por sexo no sea muy significativa aunque pareciera que los varones lo practicasen más.

En relación al conocimiento de ciertos rituales de honda raigambre mapuche, el más conocido y que ejerce mayor atracción es el rito de curación conocido como machitún, que es seguido por el palin, un juego parecido al jockey, y el nguillatun, un ritual propiciatorio que se realiza durante la cosecha. A estos tres rituales les sigue no tan distanciada la celebración del año nuevo mapuche conocido como wetrinpantu y más alejados la ceremonia fúnebre llamada eluwun, el otorgamiento de nombres por el abuelo paterno a jóvenes de cinco años conocido como lakutun y el rapto de la novia denominado ngapin.

Sin embargo, cuando se les pregunta sobre su participación en estos rituales en relación al primero de los nombrados más arriba, el 70,7\% dice 
que nunca ha participado, con respecto al segundo, 74,0\%, al tercero, $59,6 \%$, y en relación a los restantes como el wetrinpantu, $71,2 \%$, y del resto ni se pregunta. Pero así como no asisten a estos rituales, el 77,4\% tampoco acude mayormente donde los chamanes conocidos como "machi"; el 73,5\% no va a las faenas colectivas llamadas mingako y el $80,3 \%$ no acude al longko o jefe.

Lo que sí llama la atención es que el 77,4\% no acuda al machi sin embargo cuando en la $7^{a}$ pregunta se indaga por la confianza ante ciertas instituciones sobre este personaje 39,8\% dice que no sabe, 13,5\% manifiesta tenerle mucha confianza, $16,8 \%$ bastante confianza, $11,2 \%$ poca confianza y 13,0\% nada de confianza. Ante estos resultados contradictorios cabría preguntarse entonces $\dot{i}$ son tan pocos los que acuden a este personaje generalmente equiparado con un chamán?

En lo concerniente al conocimiento y representatividad que les otorgan a determinadas organizaciones mapuche tampoco se advierte que haya mucha compenetración en ellas. De Ad Mapu un 73,5 no la conoce y del $21,8 \%$ que la conoce $46,3 \%$ aduce que no lo representa. En el caso del Consejo de Todas las Tierras 53,4\% no lo conoce y del 41,6\% que lo conoce $39,9 \%$ afirma no lo representa. Con respecto a la Coordinadora AraucoMalleco, $62,4 \%$ no la conoce y del 32,7\% que la conoce $53,3 \%$ sostiene que no lo representa. En cuanto a Identidad Territorial Lafkenche, 76,3\% no la conoce y del $18,6 \%$ que sí la conoce $46 \%$ considera que no lo representa. Sobre el Consejo Pu Werken Lof Budi 80,9\% de la muestra no lo conoce y del 13,9\% que sí lo hace 51,5 asevera que no lo representa. En lo relativo a la Asociación Ñancucheo de Lumaco, 80,1\% no la conoce y del 14,9\% que si lo hace $47 \%$ aduce que no lo representa. Y, finalmente, de Kallfülkan, 83,5\% no la conoce y del $11,2 \%$ que dice conocerla 55,9 responde que no lo representa.

Sin embargo en relación a este último punto pareciera que hay mínimas discrepancias pues cuando en la pregunta 7 se solicita que respondan sobre la confianza que se les tienen a determinadas instituciones como $\mathrm{Ad}$ Mapu, entre los que afirman no saber y los que no contestan suman $69 \%$ y $6,1 \%$ expresa tenerle mucha confianza, $10,9 \%$ bastante, $7,8 \%$ poca y $6,2 \%$ nada. Lo que significa que según esta pregunta $24,9 \%$ conocería a la institución y no sólo 21,8\% como en la respuesta anterior. Con respecto al Consejo de Todas las Tierras esta vez $44,9 \%$ dice no saber y $2,4 \%$ no contesta mientras que en el caso anterior 53,4 aducía no conocerla, y así sucesivamente estas pequeñas discrepancias se repiten con las otras instituciones.

En vista que algunos estudiosos como Aldo Mascareño (2007) piensan que no hay mayores diferencias con la cultura de los no-mapuches 
salvo en el plano político, creo que hubiese sido pertinente que al menos el rubro correspondiente al machi se hubiese hecho extensivo a los no-mapuches. Asimismo es plausible que si se hubieran añadido otros indicadores como consumo de determinadas comidas, formas de cocción, enfermedades y sus respectivos tratamientos, obligaciones de guardar luto y otros más, nuevos contrastes hubieran emergido. Sin embargo comprendo que añadir demasiadas variables hubiese complicado más la encuesta. Por lo demás me parece que las diferencias que se advierten en el manejo del idioma y en el conocimiento de distintas costumbres son indicadores suficientes que dan cuenta de las peculiaridades del grupo que reivindica una condición llamada mapuche. Al menos han sido muy útiles para que Ignacio Irarrázaval y María de los Ángeles Morandé (2007) hayan podido establecer la existencia de grados de intensidad en la pertenencia a la cultura constituyéndose los de alta en paradigmas de la condición mapuche contemporánea.

Sin lugar a dudas un factor importante que recrea la condición mapuche al igual que la andina, en el caso peruano, es la convivencia en comunidades. En consecuencia no es de extrañar que el grupo de mayor intensidad mapuche sean los que se afincan en estos ámbitos. Lo que sería importante averiguar es el porqué se diluye tanto cuando se internan al mundo urbano. ¿Existen canales para estimular la interacción entre mapuches en este espacio? En el Perú existen numerosos empezando con los clubes deportivos, las cofradías, la celebración de fiestas patronales, etc. Quizá se podría pensar en algo equivalente para el caso de los mapuches o haber introducido una pregunta que midiese la interacción de mapuches con mapuches y no mapuches.

En el Perú, y en otras partes de Latinoamérica, un buen indicador de la recreación de la identidad cultural de un grupo étnico son las alianzas matrimoniales, particularmente si son endogámicas en relación a las comunidades, a la región o al grupo étnico. Si bien la encuesta incluye varias preguntas relevantes que versan sobre este tema, todas son de opinión. Creo que hubiera sido interesante preguntar a cada encuestado emparejado por la localidad de origen de él y de su compañera así como la de sus padres para determinar variantes generacionales. Quizá a este nivel se hubieran dado mayores contrastes con los no-mapuches. También hubiese sido interesante, a modo de control, no haber preguntado sólo a los mapuches sobre la opción residencial (donde se ve una ligera preferencia por la uxorilocalidad) luego del matrimonio sino también a los no-mapuches.

De hecho, el que un número tan alto de mapuches lleve dos, tres y hasta cuatro apellidos de su tradición cultural sugiere haber existido un gran nivel endogámico que no guarda correspondencia con las tendencias 
exogámicas que asoman en las respuestas a las preguntas de opinión. Que este patrón puede estarse rompiendo se deja entrever en el hecho que en el grupo de edad entre 18 y 24 años el porcentaje de los que tienen cuatro o tres apellidos mapuches decrece y que a medida que se tiene más edad aumenta.

Por otro lado llama la atención que los encuestados reivindiquen en un alto porcentaje una condición mapuche pero cuando se les pregunta por su pareja estos altos porcentajes se desplacen a una condición chilena ¿Será porque es prestigioso estar emparejado con alguien integrado a la sociedad chilena? Si éste es el caso, entonces hay una consonancia con sus respuestas a favor de la exogamia.

El mundo mapuche pareciera, pues, despertar sentimientos ambivalentes, particularmente cuando el contraste es entre lo urbano y lo rural. Llama la atención que cuando en la pregunta 30 se compara sobre el bienestar de los mapuches en el campo y en la ciudad 64,5\% afirma que los del campo están mejor que los de la ciudad pero cuando en la pregunta 27 se le pregunta al encuestado si le gustaría ir a la ciudad la mayoría responde entre sí me gustaría mucho y sí me gustaría. Igual sucede cuando en la 28 y 29 esta misma información es buscada en relación a los hijos varones y mujeres.

Es tal la atracción que ejercen las ciudades que en la pregunta 63 el 40,3\% cree que tarde o temprano los jóvenes se irán y 31,2\% piensa que desearían irse de la comunidad pero si se quedan es porque no tienen otra alternativa. Sólo el 24,9\% está interesado en quedarse sólo porque la valoran.

Aunque en las preguntas relativas a discriminación en distintos contextos (31) sus respuestas no muestran que ellos sientan una discriminación muy marcada, pudiera ser que en el fondo lo que los impulsa a buscar una mayor identificación con el conjunto nacional y con sus ámbitos más cercanos podría deberse a ciertos sentimientos de minusvalía, como ocurre con los indígenas andinos del Perú, por ser mapuches.

Es común que culturas marcadamente discriminadas por los grupos dominantes de los Estados nacionales a los que pertenecen se avergüencen de sus propias tradiciones y las traten de disimular para no ser estigmatizados. Sin embargo cuando el ser étnicamente diferente acarrea beneficios políticos y económicos, gracias a un contexto internacional que favorece el derecho a ser diferente, puede ocurrir que avergonzándose todavía de algunas de sus tradiciones reivindiquen otras que se acomodan a los gustos de aquel contexto internacional. 
Creo que una circunstancia de esta naturaleza es la que está detrás de aquel deseo de los mapuches de conservar su cultura por un lado y, por otro, de integrarse a la identidad cultural chilena como bien lo advierten Ignacio Irarrázaval y María de los Ángeles Morandé.

Dada la existencia de un contexto internacional favorable al reconocimiento de los derechos humanos, y en particular de las minorías étnicas, que promueve la creación de un fondo indígena, de convenios como el 169, etc., proclamarse descendientes de las poblaciones que existieron en la época prehispánica tiene sus ventajas. Más aun es el caso cuando los Estados nacionales se hacen eco de estas tendencias del mundo globalizado y para reafirmar sus renovados sentidos democráticos buscan legislar sobre las diferencias y reparar las asimetrías que pudieron ocurrir en el pasado. Obviamente no todos los miembros del grupo indígena son conscientes de estos nuevos resquicios que se les abre. Algunos que han podido trascender el localismo imperante pueden alcanzar a serlo muchas veces con el apoyo de sacerdotes, políticos u ONG. Éste fue el caso de la federación Shuar en Ecuador que se organizó en 1964 bajo el estímulo de los salesianos y para varias de las organizaciones indianistas que agruparon a las etnias de la Amazonía peruana. Para el caso de los mapuches es mi impresión que Ad Mapu, el Consejo de Todas las Tierras, la Coordinadora Arauco Malleco estuvieron estimuladas por agrupaciones de izquierda surgiendo por 1983 en un momento de fragor político.

Por consiguiente no le falta razón a Aldo Mascareño (2007) cuando sostiene que es en la esfera política donde las diferencias étnicas adquieren una gran relevancia, sin embargo, aunque muchas de estas diferencias puedan ser construidas al estilo de lo que nos habla Bendict Anderson (1983), si no existiera una cierta presencia de aquel pasado que permite a Irarrázaval y Morandé establecer grados de intensidad en la permanencia de la cultura mapuche, tampoco tendría mayor eco aquel discurso político, muchas veces radicalmente contestatario, moldeado por la globalización.

En realidad los mapuches tienen el privilegio de ser prácticamente la única etnia chilena con la cual se contrasta el Estado chileno. Las otras que existen, como los aimaras, no son mayormente significativas. Esta circunstancia la hace muy diferente a cualquiera de las etnias en el Perú y de otros países latinoamericanos. Obviamente tiene en común con todas ellas el no haber estado exenta de una buena dosis de discriminación y, posiblemente, de una gran pobreza económica que se ve en la precariedad de los servicios con que cuentan. Pero por otro lado difícilmente en estas etnias porcentajes tan altos de sus poblaciones tengan televisores en colores y celulares.

Mi impresión es que gracias a la mencionada posición privilegiada de la que gozan, y quizá a cierta dosis de individualismo de su acervo 
cultural, su interacción con el conjunto nacional ha sido más intensa, lo que puede haber facilitado un grado mayor de absorción de las reglas de juego de aquel conjunto que otras etnias latinoamericanas.

Sin embargo siguen siendo mapuches y al parecer lo serán por un buen tiempo mientras parte de ellos sigan todavía vinculados a un régimen de comunidades que favorezcan las interacciones interpersonales y valoren el legado cultural de los ancestros. Pero aquel $40 \%$ que todavía vive en estos conglomerados rurales ¿hasta cuándo lo seguirá haciendo? Todo depende de una revaloración de ese estilo de vida en tanto se logre descubrir que pueden adecuarse a la modernidad en condiciones más óptimas de las que han tenido. Esto significa que más allá de adquirir celulares o televisores en colores deberán mejorar significativamente su infraestructura doméstica, la calidad de sus servicios educativos y sanitarios y desarrollar actividades económicas que alcancen cauces adecuados para participar con holgura en las redes comerciales nacionales e internacionales.

Reconciliar la modernidad con la tradición no es una entelequia. Muchos pueblos lo han logrado. Recientemente vemos que una tribu norteamericana como los seminola ha pagado más de 900 millones de dólares por la cadena Hard Rock. Es cierto que en Sudamérica la tradición colonialista impone retos más difíciles a los pueblos indígenas pero, por otro lado, la globalización, aparte de abrir nuevas posibilidades a estos grupos en el campo político, pone al servicio también otros medios como recursos tecnológicos que bien manejados pueden traer consecuencias positivas insospechadas.

Según la encuesta preparada por el Centro de Estudios Públicos, los mapuches si bien en conjunto mantienen altos grados de pobreza parecen marchar claramente hacia una modernización acelerada donde todavía se da un cierto equilibrio entre sus sentimientos de ser mapuches y ser parte del conjunto nacional chileno. Sin embargo, para mayor seguridad en los resultados obtenidos pienso que se debería completar este estudio con una encuesta aplicada a igual número de personas no-mapuches pero que se encuentran en áreas más alejadas. Asimismo no estaría de más confrontar estos resultados con los de alguna etnografía contemporánea detallada que haya contemplado aspectos como los que he ventilado en relación a los pueblos andinos. Si todavía no se ha hecho, valdría la pena intentarlo pues ello supondrá un mejor control de la información a través de interacciones interpersonales con permanencia en el tiempo que es un requisito indispensable para ganarse la confianza de los informantes y afinar el talento indagador. 


\section{BiBLIOGRAFÍA}

Anderson, Benedict: Comunidades Imaginadas. FCE, 1993.

Centro de Estudios Públicos (CEP): "Estudio de Opinión Pública: Los Mapuche Rurales y Urbanos Hoy. Mayo 2006”. Santiago: CEP, 2006.

Fuenzalida, Fernando: “Poder, Raza y Etnia en el Perú Contemporáneo”. En Fernando Fuenzalida, Enrique Mayor, Gabriel Escobar, et al., El Indio y el Poder. Lima: Instituto de Estudios Peruanos, 1970.

Garcilaso de la Vega, Inca: “Los Comentarios Reales de los Incas”. En Obras Completas del Inca Garcilaso de la Vega, T. II. Biblioteca de Autores Españoles, 1960.

Instituto Nacional de Estadísticas (INE): “Censo 2002”. Santiago, INE.

Irarrázaval, Ignacio y María de los Ángeles Morandé: “Cultura Mapuche: Entre la Pertenencia Étnica y la Integración Nacional”. En Estudios Públicos, 105 (verano 2007).

Mascareño, Aldo: “Sociología de la Cultura. La Deconstrucción de lo Mapuche”. En Estudios Públicos, 105 (verano 2007).

Mauss, Marcel: “Ensayo sobre los Dones”. En Marcel Mauss, Sociología y Antropología. Ed. Tecnos, 1971.

Palomino, Salvador: El Sistema de Oposiciones en la Comunidad de Sarhua. Lima: Ed. Pueblo Indio, 1984.

Titu Cusi Yupanqui: Relación de la Conquista del Perú. Lima: Ediciones de la Biblioteca Universitaria, 1973. 